\title{
Managing the crack energy dissipation as a way to increase the durability of fine-grained limestone concrete
}

\author{
Vladimir Belov ${ }^{1, *}$, Pavel Kuliaev ${ }^{1}$, and Temur Barkaya ${ }^{1}$ \\ ${ }^{1}$ Tver State Technical University, Civil Construction Department, 22, Af. Nikitin Quay, Tver, \\ 170026, Russia
}

\begin{abstract}
The durability of fine-grained concrete is associated with the process of cracking. The propagation of cracks depends on the energy dissipation rate. The results of the tests presented show the effectiveness of a limestone microdispersed filler and superplasticizer for increasing the durability of fine-grained carbonate concrete.
\end{abstract}

\section{Experiment}

\subsection{Introduction}

The use of limestone crushed stone screenings together with microdispersed limestone filler and superplasticizer to improve the performance and technological properties of finegrained concrete, and increase the level of durability, is currently relevant for the construction industry. Fine-grained limestone concrete is a heterogeneous solid composite consisting of two or more components: reinforcing elements and a binding matrix [1]. From the very beginning, attempts were made to obtain analytical relationships between the durability, crack resistance of such concrete and the distribution of particles in the mixtures.

Limestone powder is a good modifier of the physical and chemical properties of finegrained carbonate concrete and a substitute for the main binder. This is due to the ability of limestone powder to work together with a superplasticizer and other ingredients in a concrete body that consists of a matrix, water, binder, various water-reducing additives, and an internal structure capable of organizing the dissipation of internal energy for the formation and growth of cracks [2,3]. The type of dissipation studied in this paper is associated with internal friction, and has an important role in civil construction, and in particular in cases of thin-walled structures, and structures that work on dynamic loads.

Energy dissipation can be considered as an internal change in the structure, or so-called distributed dissipation, due to the characteristic of the material and internal friction, which plays an important role in the case of modification of the dynamic viscosity of the material.

Fine-grained carbonate concrete is usually considered as an elastic-visco-plastic material [4], and its internal matrix as an elastic-plastic medium [5].

\footnotetext{
Corresponding author: vladim-bel@ya.ru
} 
Distributed dissipation is associated with concrete damage, friction of macro-crack faces caused by constant deformation of plasticity-creep. But internal friction takes a special place, since it is not associated with irreversible changes in the microstructure of concrete. Dissipation associated with internal damage and permanent elastic-plastic deformations can be considered as a critical event, but it also has a positive effect on slowing the growth of main cracks [6].

The destruction of concrete occurs as a result of sprouting of one of the cracks or a cluster of branched cracks [7] through its structure through fillers (under dynamic influence) or through the matrix, skirting the filler grains (under static loading). Tver state technical university conducted a study on improving the durability and crack resistance of fine-grained carbonate concrete depending on the ratio of cement to limestone and the amount of superplasticizer. This study discusses the synergy effect of the combined use of a limestone microfiller and a superplasticizer, which increase the rate of dissipation of crack propagation energy. The rate of dissipation of the crack propagation energy was estimated by the values of the crack formation stresses and the stress intensity coefficient for ten samples of fine-grained carbonate concrete with and without a limestone microfiller.

\subsection{Materials}

Ten concrete blocks measuring $7 \times 7 \times 7 \mathrm{~cm}$ were tested for compression. Limestone filler is a by-product of crushing limestone rocks. Limestone grains ranging in size from 5 to 0.05 $\mathrm{mm}$ were used as a filler.

\subsection{Technics}

The strength, crack resistance, and instantaneous deformations of fine-grained limestone concrete were analyzed on a special stand (Fig. 1.).

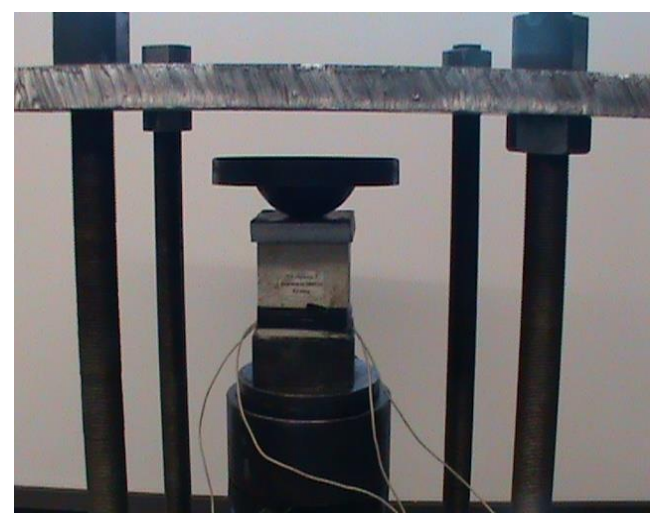

Fig. 1. Test unit and sample with electrical sensors on two sides

The appearance of cracks was recorded using electric strain gauges. The accuracy of the measurements was 10-7. To determine the crack resistance, the given stress intensity coefficient was used, taking into account the features of concrete as a non-uniform composite material with a complex conglomerate structure consisting of a cluster of microcracks and a large main crack.

$$
K_{r}=\left(1-\mu^{2}\right) \times K_{1}^{2} / E
$$




$$
K_{1}=\sigma \times \sqrt{\pi \times l}
$$

where 1 is the half -width of the main crack, $\mu$ is the Poisson's ratio, assumed to be 0.3 , and $\sigma$ is the crack -forming stress, E-modulus of elasticity.

\section{Test results}

Table 1 below shows the composition of the mixture.

Table 1. Composition of the mixture, $\mathrm{kg} / 1 \mathrm{~m}^{3}$

\begin{tabular}{|c|c|c|c|c|c|}
\hline $\begin{array}{c}\text { № } \\
\text { mixtures }\end{array}$ & $\begin{array}{c}\text { Binder, } \\
\text { кg }\end{array}$ & $\begin{array}{l}\text { Aggregates, } \\
\mathbf{k g}\end{array}$ & Cement, кg & $\begin{array}{l}\text { Limestone } \\
\text { filler, } \mathrm{kg}\end{array}$ & $\begin{array}{c}\text { SP-1, } \\
\text { кg }\end{array}$ \\
\hline 1 & 672 & 1528 & 672 & 0 & 0 \\
\hline 2 & 672 & 1528 & 336 & 336 & 0 \\
\hline 3 & 672 & 1528 & 672 & 0 & 5,04 \\
\hline 4 & 672 & 1528 & 672 & 0 & 6,72 \\
\hline 5 & 672 & 1528 & 672 & 0 & 3 \\
\hline 6 & 672 & 1528 & 472 & 200 & 0 \\
\hline 7 & 672 & 1528 & 472 & 200 & 2,11 \\
\hline 8 & 672 & 1528 & 553 & 119 & 4,15 \\
\hline 9 & 672 & 1528 & 336 & 336 & 0,89 \\
\hline 10 & 672 & 1528 & 336 & 336 & 2,52 \\
\hline
\end{tabular}

Table 2. Below shows the results of the tests

\begin{tabular}{|c|c|c|c|}
\hline \multirow{2}{*}{$\begin{array}{c}\text { № } \\
\text { mixture }\end{array}$} & \multicolumn{2}{|c|}{$\begin{array}{c}\text { Crack-forming stress and compressive } \\
\text { strength }\end{array}$} & \multirow{2}{*}{$\begin{array}{l}\text { Stress intensity factor } \\
\qquad \kappa_{r}, \mathrm{~N} \times \mathbf{M}\end{array}$} \\
\hline & $\sigma$, МПа & $R$, МПа & \\
\hline 1 & 34,4 & 44,1 & 0,00099 \\
\hline 2 & 23,3 & 27,8 & 0,00372 \\
\hline 3 & 31,5 & 42,6 & 0,00075 \\
\hline 4 & 36,7 & 48,5 & 0,00073 \\
\hline 5 & 31,9 & 43 & 0,00238 \\
\hline 6 & 28,2 & 35,6 & 0,00085 \\
\hline 7 & 34,1 & 41,2 & 0,00106 \\
\hline 8 & 40,1 & 46,8 & 0,00092 \\
\hline 9 & 30,3 & 37,3 & 0,00137 \\
\hline 10 & 30 & 37,1 & 0,00115 \\
\hline
\end{tabular}

The values of the reduced stress intensity factor $\mathrm{K}_{\mathrm{r}}$ for samples containing limestone filler and superplasticizer are higher than for samples without them. In this case, plastic zones are formed at the main crack and at the microcracks in the basin of the latter, which deprive the main crack of energy for further growth, increasing the dynamic viscosity and internal friction. This is the essence of the phenomenon of limiting crack formation through the mechanism of energy dissipation using limestone and superplasticizer SP-1.

The following figures show the relationship between the stress intensity factor $K_{r}$ $(\times 1000)$, the content of the superplasticizer, and the content of the limestone filler and the water-cement ratio. 


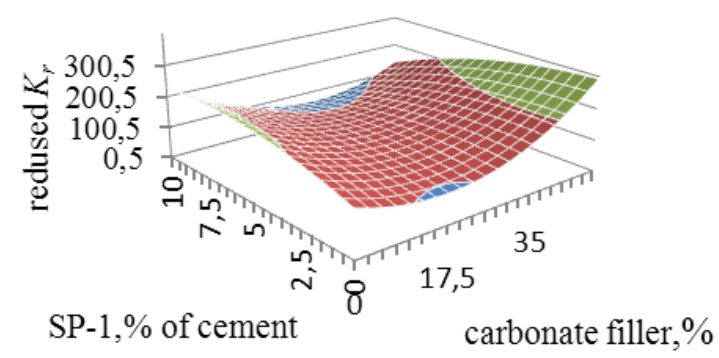

Fig. 2 The ratio between the stress intensity coefficient Kr, the amount of superplasticizer SP-1 and the limestone filler.

The optimal amount of limestone filler as a partial replacement for the binder is $18 \%$.

In tests, the superplasticizer SP-1 was used in an amount of $0.75 \%$ of the volume of cement. Below is a graph of the dependence of the compressive strength on the amount of limestone filler in the concrete test.

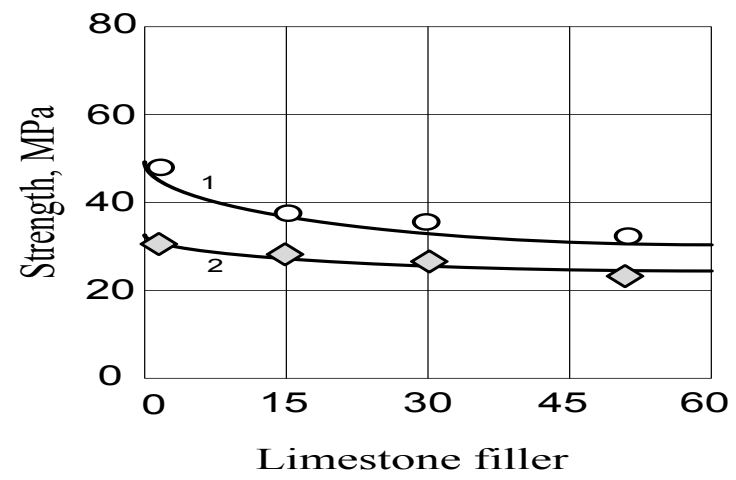

Fig. 3. Compressive strength-curve 1 and crack- forming stresses -curve 2 depending on the content of limestone filler in carbonate fine -grained concrete.

It can be seen that for samples containing limestone filler, the gaps between the crackforming stresses and the strength values are narrower. This is due to better distribution of cement particles, micro-filler and superplasticizer and filling of air and capillary pores with them. The optimal amount of superplasticizer should compensate for the excess amount of ultrafine limestone particles, which increase the air-trapping capacity of the cement dough (the puffing effect).

It was found that the limestone filler and superplasticizer SP-1 play a positive role in relation to the strength characteristics of limestone fine-grained concrete.

\section{Summary and prospects}

Limestone aggregate, being manufactured in local quarries, provides good efficiency and a cheap replacement for cement. Easily crushed limestone powder usually has a wide range of granulometric composition, which contributes to the process of filling ultra-voids between cement particles, thereby reducing the need for water, improving the uniformity of the solution and unifying the microstructure of the concrete matrix. This leads to an 
increase in durability and crack resistance, without significant loss of technological properties, which indicates large values of the stress intensity coefficient $\mathrm{Kr}$ for samples containing limestone. Increased crack resistance of limestone fine-grained concrete is also achieved due to better packing of particles inside the concrete matrix, and the decrease in porosity is caused by the transfer of microcracks from air and capillary areas to plastic microzones.

\section{References}

1. V.V. Belov, I.V. Obraztsov, T.B. Novichenkova, Capillary structure formation of raw composites based on mineral binders, Nanotechnology in construction: scientific online journal, v. 4(8), 23-36 (2010)

2. U. El Shamy, C. Denissen, Microscale energy dissipation mechanisms in cyclicallyloaded granular soils, Geotechnical and Geological Engineering, 30(2), 343-361 (2012)

3. G. De Schutter, Influence of limestone filler as a mineral additive in self-compacting concrete, Belgium Magnel laboratory of concrete research (36 Conference on Our World in concrete \& Structures, Singapore, 14-16/08, 2011)

4. G. Pijaudier-Cabot, K. Haidar, J-F. Dubé, Non-local damage model with evolving internal length, International Journal for Numerical and Analytical Methods in Geomechanics, 28(7-8), 633-652 (2004)

5. Z.P. Bažant, G. Zi, A microplane constitutive model for porous isotropic rocks, International Journal for Numerical and Analytical Methods in Geomechanics, 27(1), pp. 25-47 (2013)

6. D. Scerrato, I. Giorgio, A. Della Corte, A. Madeo, A. Limam, A micro-structural model for dissipation of phenomena in the concrete, Wiley, 39 (18), pp. 2037-2052 (2015)

7. Y.S. Alam, P. Kotronis, A. Loukili, Crack propagation and size effect in concrete using a non-local damage model, Engineering Fracture Mechanics, 109, 246-261 (2013) 